\title{
Communication between myocytes and fibroblasts in cardiac remodeling in angiotensin chimeric mice
}

\author{
Taiji Matsusaka, ${ }^{1,3}$ Hideyuki Katori, ${ }^{1}$ Tadashi Inagami, ${ }^{2}$ Agnes Fogo, ${ }^{4}$ \\ and Iekuni Ichikawa ${ }^{1,3}$ \\ ${ }^{1}$ Department of Pediatrics, \\ ${ }^{2}$ Department of Biochemistry, \\ ${ }^{3}$ Department of Medicine, and \\ ${ }^{4}$ Department of Pathology, Vanderbilt University School of Medicine, Nashville, Tennessee 37232-2584, USA
}

Address correspondence to: Taiji Matsusaka, Department of Pediatrics, Vanderbilt University Medical Center, MCN C4204, Nashville, Tennessee 37232-2584, USA. Phone: (615) 322-7931; Fax: (615) 322-7929; E-mail: taiji.matsusaka@mcmail.vanderbilt.edu.

Received for publication August 27, 1998, and accepted in revised form March 23, 1999.

\begin{abstract}
To characterize the mode of action of angiotensin II (Ang II) in cardiac remodeling, we generated chimeric mice that are made of both homozygous Ang II receptor type 1A gene (Agtr1a) null mutant cells and Agtr1a intact cells expressing the lacZ gene (ROSA26). Both Agtr1a null and intact myocytes and interstitial cells independently form areas that are randomly distributed throughout the heart. The distribution of ROSA26 cardiomyocytes overlaps completely with that of Ang II binding, indicating that the majority of Ang II receptors reside on cardiomyocytes. When Ang II ( $1 \mathrm{ng} / \mathrm{g}$ body weight $/ \mathrm{min})$ was infused for 2 weeks, mice developed mild to moderate hypertension. The proliferating cardiac fibroblasts identified by bromodeoxyuridine staining were present predominantly in the areas surrounded by Agtrla intact cardiomyocytes. When control chimeric mice made of wild-type cells and ROSA26 cells (i.e., both carrying intact Agtr1a) were infused with Ang II, fibroblast proliferation was found equally in these cardiomyocyte types. When compared with Agtrla null mutant chimeras, the control chimeras had more extensive cardiac fibrosis, most prominently in perivascular regions. Therefore, in response to Ang II, cardiac fibroblasts proliferate through both the local and systemic action of Ang II. Importantly, the former is determined by the Ang II receptor of neighboring cardiomyocytes, indicating that a communication between myocytes and fibroblasts plays an important role during Ang II-dependent cardiac remodeling.
\end{abstract}

J. Clin. Invest. 103:1451-1458 (1999).

\section{Introduction}

Cardiac myocytes are surrounded by a fine network of collagen fibers that are generated primarily by cardiac fibroblasts (1). In pathologic situations involving hypertrophic reaction of cardiomyocytes, such as pressure overload or postmyocardial infarction, cardiac fibroblasts proliferate and extracellular matrix proteins accumulate disproportionately and excessively (2). This process, called reactive fibrosis, leads to increased ventricular stiffness, and hence diastolic, and then systolic, dysfunction of the heart (3). In addition, it may disrupt the cardiac conducting system $(4,5)$. Thus, cardiac fibrosis is recognized as a key process that links pathologic cardiac hypertrophy to heart failure.

Research increasingly shows that angiotensin II (Ang II) is involved in cardiac fibrosis. Thus, treatment with angiotensin-converting enzyme (ACE) inhibitors or Ang II type 1 (AT1) receptor antagonists attenuates the cardiac fibrosis that occurs in experimental myocardial infarction (6-8), renovascular hypertension (9), and genetic hypertension (10). Also, in humans, ACE inhibitors exert salutary effects on long-term survival of patients after myocardial infarction $(11,12)$. More directly, chronic infusion of Ang II in rats was shown to induce cardiac fibrosis through the AT1 receptor (2).

Many clinical and experimental studies show that ACE inhibitors or AT1 antagonists have more beneficial effects on the heart than expected, resulting solely from their blood pressure-lowering effect $(7,11,12)$. Studies also point to additional mechanisms, other than increasing cardiac afterload, for Ang II-dependent cardiac fibrosis $(2,13$, 14). Therefore, it is believed that Ang II has a direct local effect on cardiac tissue, independent of its systemic hemodynamic effect. Other evidence supporting this notion comes from in vitro studies showing that the AT1 receptor is present on cardiac fibroblasts and that Ang II directly promotes DNA and protein synthesis in cultured cardiac fibroblasts (15-22). However, it is not fully elucidated whether, and how, such a local mechanism contributes to the process of cardiac fibrosis in in vivo settings.

To understand the nature of the local and systemic mechanisms of the cardiac fibrosis dependent on Ang II, we have generated chimeric mice that are made of 2 genetically different types of cells: one with and the other without the AT1A receptor gene (Agtr1a). AT1A is the predominant subtype of the AT1 receptor in the mouse heart $(23,24)$. To identify cells with and without intact Agtr1a, we used the ROSA26 transgenic mouse strain to engineer the chimeric mouse so that the marker gene lac $Z$ is expressed in all cells with intact Agtrla. Within a given chimeric mouse, the 2 types of cells are exposed to the same systemic environment, whereas only the cells that have intact AT1A gene are subjected to local actions of the Ang II. We infused Ang II chron- 
ically in these chimeric mice and evaluated the local cardiac interstitial cell reactions. In this study, we found that a novel mode of cardiac tissue action of Ang II, specifically communication between cardiomyocytes and interstitial cells, plays an important role in the process of Ang II-induced cardiac remodeling.

\section{Methods}

Mice used for embryo donors. In the past, we generated 2 lines of the AT1A receptor-deficient (Agtr1 $\left.a^{-/-}\right)$mice (25). We used a line with a mixed genetic background of C57BL/6 and 129/Ola, without the lac $Z$ gene, in the present study to generate chimeric mice. None of these mice in our Agtrla $a^{-/}$colony are albinotic. ROSA26 transgenic mice (ROSA), originally generated by P. Soriano and colleagues $(26,27)$, are kind gifts from David Threadgill. These mice have a mixed genetic background of C57BL/6, 129/Sv, and ICR. All of the ROSA2 6 mice in our colony are albinotic. Wildtype (129/Sv $\times$ C57BL/6) F1 mice were purchased from The Jackson Laboratory (Bar Harbor, Maine, USA).

Generation of chimeric mice. To generate Agtrla $a^{-/-} \leftrightarrow R O S A$ mice, Agtr $1 a^{-/-}$and ROSA26 embryos (2.5 days postcoitus) were harvested and aggregated (28). After the embryos were cultured for 58 hours, the chimeras were transferred into the uterus of 2.5 days postcoitus pseudopregnant ICR females. For generating Agtr $1 a^{+/+} \leftrightarrow R O S A$ mice, embryos obtained from mating between $(129 / \mathrm{Sv} \times \mathrm{C} 57 \mathrm{BL} / 6) \mathrm{F} 1$ males and females were aggregated with ROSA2 6 embryos.

Ang II binding autoradiography. Serial adjacent cryosections (16 $\mu \mathrm{m}$ ) of Agtr1 $a^{-/-} \leftrightarrow R O S A$ mice tissues were used for Ang II binding autoradiography and $\beta$-galactosidase (lacZ) staining. For Ang II binding autoradiography, sections were preincubated in a binding buffer ( 5 mM EDTA, $0.005 \%$ bacitracin [Sigma Chemical Co., St. Louis, Missouri, USA], 2\% BSA [Sigma Chemical Co.], and AT2 antagonist PD123319 [3 $3 \mu \mathrm{M}]$ in PBS) for 15 minutes at room temperature and then incubated in the binding buffer containing $0.5 \mathrm{nM}\left[{ }^{125} \mathrm{I}_{-} \mathrm{Sar}^{1}-\mathrm{Il} \mathrm{e}^{8}\right]$ Ang II (Du Pont NEN Research Products, Boston, Massachusetts, USA) at room temperature for 2 hours. After incubation, tissues were washed 4 times in ice-cold $50 \mathrm{mM}$ Tris-HCl ( $\mathrm{pH}$ 7.6) for 1 minute each, rinsed in ice-cold distilled water, air dried, and then fixed in formaldehyde vapor at $37^{\circ} \mathrm{C}$ for 2 hours. Tissue slides were dipped in $\mathrm{K}-5$ emulsion (Ilford Ltd., Basildon, Essex, United Kingdom) diluted with a 2fold volume of $2 \%$ glycerol and exposed at $4^{\circ} \mathrm{C}$ for 5 days. Slides were developed in 1.6\% D-19 (Eastman Kodak, Rochester, New York, USA), stopped in $1 \%$ acetic acid, fixed in $30 \%$ sodium thiosulfate, and counterstained with $0.2 \%$ toluidine blue $\mathrm{O}$.

$\beta$-galactosidase staining. Cryosections of the heart tissue were immediately fixed in a fixation solution (2\% glutaraldehyde, $0.01 \%$ sodium deoxycholate, $0.02 \%$ IGAEPAL-CA630 [Sigma Chemical Co.], $1 \mathrm{mM} \mathrm{MgCl}$, in PBS] for 5 minutes at $4^{\circ} \mathrm{C}$, rinsed in PBS 3 times for 30 minutes, and incubated in a staining solution $[0.01 \%$ sodium deoxycholate, $0.02 \%$ IGAEPALCA630, $1 \mathrm{mM} \mathrm{MgCl}_{2}, 2 \mathrm{mM} \mathrm{K}_{3} \mathrm{Fe}(\mathrm{CN})_{6}, 2 \mathrm{mM} \mathrm{K}_{4} \mathrm{Fe}(\mathrm{CN})_{6}, 1$ $\mathrm{mg} / \mathrm{mL}$ X-Gal (GIBCO BRL, Gaithersburg, Maryland, USA), in PBS] at $37^{\circ} \mathrm{C}$ for 10 hours.

Chronic Ang II infusion. Eleven Agtr1 $a^{-/-} \leftrightarrow R O S A$ mice and 6 Agtr1 $a^{+/+} \leftrightarrow R O S A$ mice (7-26 weeks old), in which 1-80\% of the fur is pigmented, were infused with Ang II; $2 \mathrm{Agtr} 1 \mathrm{a}^{-/-} \leftrightarrow R O S A$ mice died at the 10th and 13th day, respectively, and were not analyzed. Ang II (1 ng/g body weight/min; Sigma Chemical Co.) was infused into the mice subcutaneously by osmotic minipump (model 2002; Alza Corp., Palo Alto, California, USA) for 14 days. All mice had a second pump containing bromodeoxyuridine (BrdU) $(50 \mathrm{mg} / \mathrm{mL})$ implanted subcutaneously for the 2-week study period. On the 13th day of Ang II infusion, PE10 tubing, heated and tapered at one end, was inserted into the right carotid artery under anesthesia with ketamine and xylazine $(100 \mathrm{mg} / \mathrm{kg}$ and $10 \mathrm{mg} / \mathrm{kg}$ body weight intraperitoneally, respectively). Twenty hours after the surgery, blood pressure in the conscious state was measured with a transducer (CDXIII; Cobe Laboratories Inc., Lakewood, Colorado, USA) that was connected to a BP Analyzer (Micro-Med Inc., Louisville, Kentucky, USA). After the experiment, the Ang II and BrdU pumps were opened and the volume of residual fluid in the inner capsules was examined. Only $15-20 \%$ of the original volume of Ang II or BrdU solution remained, confirming that all pumps worked properly.

As controls, 4 Agtr $1 a^{-1} \leftrightarrow R O S A$ mice and 4 wild-type mice with a mixed background of C57BL/ 6 and 129 were infused with saline and BrdU for 2 weeks. In addition, 3 Agtrl $a^{-/-}$mice were infused with Ang II ( $1 \mathrm{ng} / \mathrm{g}$ body weight $/ \mathrm{min}$ ) and BrdU for 2 weeks.

Morphometric analysis of collagen. To quantitate the total collagen deposition, which occurred focally, a modified point counting method was used on Masson trichrome-stained sections. For each chimeric heart, nonoverlapping visual fields were fixed along a 0.45 -mm grid throughout the tissue. Using a $\times 20$ objective, $\leq 121$ points were observed in each visual field. In total, $>24,000$ points were observed in 2 nonadjacent sections of each heart. All aniline blue-positive points were counted and represented as numbers per 1,000 points, which was designated as total collagen index. All control mice without Ang II infusion had a score of $<0.5$ with this method.

To quantitate periarterial fibrosis, all cross-sections of coronary arteries in 2 nonadjacent Masson-stained sections were observed and scored from 0 to 2 in the following manner: score 2 , ratio adventitia/media ratio $>4$; score 1 , adventitia/media $>2$ and $\leq 4$, or collagen extending into surrounding tissue; and score 0 , adventitia/media $\leq 2$ and no extension of collagen. The average score of all coronary arteries was calculated for each heart. All control mice without Ang II infusion had a score of 0 according to this method.

Immunostaining for BrdU. Cardiac cryosections of chimeric mice infused with Ang II and BrdU were first stained for lacZ and then further stained for BrdU. Immunostaining of BrdU was performed using a BrdU-staining kit (Oncogene Research, Cambridge, Massachusetts, USA). The intestine was stained for BrdU as a positive control. All intestinal epithelial nuclei had positive staining for BrdU.

Other antibodies used in this study. Anti- $\alpha$-smooth muscle cell actin (DAKO A/S, Glostrup, Denmark) and anti-TGF- $\beta 1$ antibody (Santa Cruz Biotechnology Inc., Santa Cruz, California, USA) were also used in this study.

Morphometric analysis of interstitial cell proliferation. Ten visual high-power fields containing similar areas of ROSA and nonROSA cardiomyocytes were randomly chosen for each cardiac region (anterior, posterior, and lateral walls of left ventricle, septum, right ventricle) in each chimeric heart. Areas around coronary arteries and areas with massive fibrosis were not chosen. In each field, all BrdU-positive nuclei and BrdU-negative interstitial cell nuclei that do or do not have contact with lacZstained cardiomyocytes were counted separately. Interstitial nuclei, which are flat and small, were easily distinguishable from round, large nuclei of cardiomyocytes. The ratio of the number of BrdU-positive nuclei to total number of interstitial nuclei, designated BrdU-positivity ratio, was calculated for each area in each chimeric mouse.

Statistical analysis. Comparisons between non-ROSA and ROSA cardiomyocyte areas were made using the $\chi^{2}$ test. A value of $P<0.05$ was considered significant.

\section{Results}

Clonal pattern of cardiocytes in the chimeric heart. Two types of chimeric mice were generated by the embryo aggregation method. Figure 1 illustrates the key genetic aspects of the chimerism of these mice. One type of chimeric mouse (abbreviated as Agtr1a $a^{-/} \leftrightarrow R O S A$ mouse) (Figure 1a) is 
made of homozygous AT1A receptor gene (Agtr1a) null mutant $\left(\right.$ Agtr1 $\left.a^{--}\right)$cells and ROSA26 transgenic (ROSA) cells. The Agtr1a ${ }^{-/}$cells have no intact Agtr1a or the marker gene lacZ, while the ROSA cells have both Agtrla and lac $Z$ genes. In the chimeric heart, blue lacZ staining identifies the cells of ROSA26 transgenic mouse origin, as all cardiac cells in the heart of nonchimeric ROSA2 6 transgenic mice are stained for lacZ. Moreover, this lacZ staining was not affected by the infusion of Ang II (data not shown), a protocol used in the present study. The other type of chimeric mouse (abbreviated as Agtr $1 a^{+/+} \leftrightarrow R O S A$ mouse) (Figure 1b) is made of wild-type and ROSA26 cells, which both carry intact Agtrla. Both types of these chimeric mice have varying percentages of pigmented fur, reflecting the percentage of ROSA cells in melanocytes, ranging between $0 \%$ and $100 \%$.

Both Agtr1 $1 a^{-/-} \leftrightarrow R O S A$ and Agtr $1 a^{+/+} \leftrightarrow R O S A$ mice showed similar lacZ staining patterns. Thus, lacZ staining of the heart from both types of chimeric mice had distinct staining of cardiomyocytes. In cross-sections, each cardiomyocyte was either intensely stained or completely negative, with no intermediate or vague staining (Figure 2a). The distribution pattern of each genotype of cardiomyocytes was clustered and patchy. There was a tendency for the contribution of ROSA cells to the whole cardiac tissue to be similar to that of the skin estimated by coat color. However, the magnitude of the chimerism in the heart cannot be accurately estimated before autopsy, and the pattern of chimerism was random and somewhat unpredictable.

Vascular smooth muscle cells of coronary arteries also showed clear and intense staining. Thus, as with cardiomyocytes, some vascular smooth muscle cells were intensely stained for lacZ, whereas others are completely negative. In some areas, lacZ-positive vascular smooth muscle cells were surrounded by lacZ-negative cardiomyocytes (Figure 2b), indicating that the clonal patterns of cardiomyocytes and coronary vascular smooth muscle cells were not associated with each other.

In contrast, the lac $Z$ staining of each interstitial cell was less clearly delineated because of both its small cell size and the relatively low expression of the lac $Z$ gene. LacZ-positive interstitial cells resided in the area of lacZnegative cardiomyocytes (Figure 2c). On the other hand, in the area of ROSA cardiomyocytes, it was difficult to determine the lac $Z$ positivity in sparse interstitial cells in ordinary conditions; this is due to the radiation of blue color from neighboring ROSA cardiomyocytes or the overlapping interstitial cells on ROSA cardiomyocytes. When fibrosis was induced in $A g \operatorname{tr} 1 a^{+/+} \leftrightarrow R O S A$ mice by infusion of Ang II, clusters of lacZ-negative interstitial cells became visible between ROSA cardiomyocytes (Figure $2 \mathrm{~d}$ ), so that the presence of nonROSA cardiac fibroblasts in the ROSA cardiomyocyte area could be recognized without affecting the general pattern of lacZ staining. Also, in periarterial regions of chimeric mice in both basal and Ang II-infused conditions, some fibroblasts were stained for lacZ; the lacZ staining pattern was not associated with that of surrounding cardiomyocytes or neighboring vascular smooth muscle cells.

Collectively, these findings indicate that the clonal distribution patterns of the cardiomyocytes, fibroblasts, a

EXPERIMENTAL Agtr1a- $-\leftrightarrow R O S A$ mouse

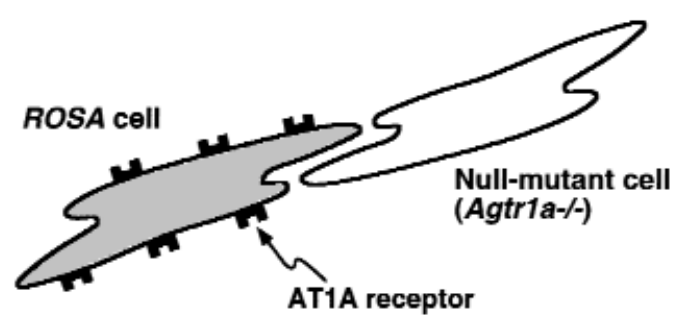

b

CONTROL Agtr1a+/+ $\leftrightarrow$ ROSA mouse

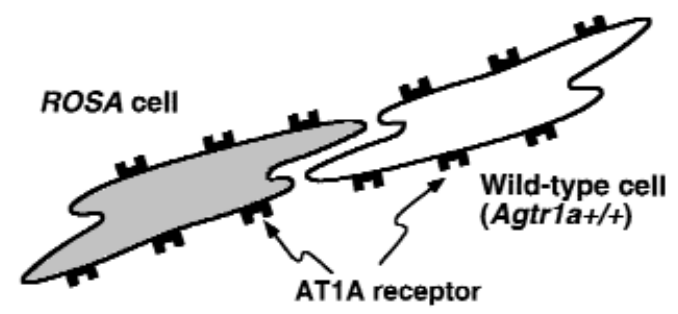

Figure 1

Schematic presentation of the cells constituting the 2 kinds of chimeric mice engineered in the present study. In the Agtr1 $1 a^{-1-} \leftrightarrow R O S A$ chimeric mouse (a), which is made of ROSA26 transgenic (ROSA) cells and Agtr1 $1 a^{-/-}$cells, only lacZ-positive cells (derived from a ROSA26 transgenic mouse) express AT1A receptors, whereas lacZ-negative cells lack AT1A receptors because of null mutation of both of their Agtr1a alleles by gene targeting. A comparison between the lacZ-positive and lacZ-negative cells within a given tissue allows identification of the AT1A receptor-dependent local cellular effect of Ang II. In the Agtr1 $a^{+/+} \leftrightarrow R O S A$ chimeric mouse (b), which is made of ROSA cells and wild-type cells, both lacZ-positive and lacZ-negative cells express AT1A receptors. Comparison between the lacZ-positive and lacZ-negative cells in this control chimera allows detection of the effect of the ROSA26 mutation and the genetic background of ROSA and non-ROSA cells, which may be significant independently of AT1A receptors because both cells have the intact Agtr1a gene.

and vascular smooth muscle cells in the chimeric heart are not associated with each other.

Ang II binding autoradiography in the Agtr1a-/- $\leftrightarrow R O S A$ chimeric hearts. To ascertain the cellular expression pattern of the AT1 receptor in the heart, we performed binding autoradiography in the Agtr1 $a^{-/-} \leftrightarrow R O S A$ heart using

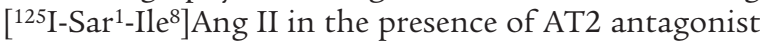
PD123319. Uniform and intense Ang II binding was observed throughout the heart of ROSA26 transgenic mice, which have the intact Agtrla gene; however, no signal was detected in the Agtr1a $a^{-/}$heart (data not shown), confirming that AT1B receptor - the other subtype of mouse AT1 receptor - is essentially negligible in the mouse heart, as reported previously $(23,24)$. The pattern of Ang II binding in the Agtr1 $a^{-/-} \leftrightarrow R O S A$ heart overlapped completely

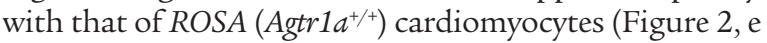
and $\mathrm{f}$. Therefore, in cardiomyocytes, lacZ expression coincided with AT1 receptor expression. More importantly, these results also demonstrate that the majority of AT1 



Figure 2

Clonal pattern of lacZ-positive cells in the chimeric heart (a-d). Heart tissues from an Agtr1 $a^{-/-} \leftrightarrow R O S A$ mouse (a-c) or from an Agtr1 $a^{+/+} \leftrightarrow R O S A$ mouse infused with Ang II (d) were stained with X-gal and nuclear Fast Red. Each cardiomyocyte is either intensely stained (blue) for lacZ or is completely negative, and the distribution pattern of each type of cardiomyocyte is clustered (a). In b, a lacZ-positive coronary artery is surrounded by lacZ-negative cardiomyocytes, indicating that the clonal patterns of these 2 types of cells are not associated with each other. In c, lacZ-stained cardiac interstitial cells are observed among lacZ-negative cardiac myocytes. In $\mathbf{d}$, a cluster of fibroblasts, which is induced by Ang II infusion, is surrounded by lacZ-positive cardiomyocytes. Note that the left half (arrowheads) is stained for lacZ, while the right half (arrows) is not. AT1 receptor distribution in the Agtr1 $a^{-/-} \leftrightarrow R O S A$ heart (e and f). (e) LacZ and nuclear Fast Red staining. Most lacZ staining (original blue color is darkened by enhancing contrast) recognized at this magnification is in cardiomyocytes. (f) $\left[{ }^{125}\right.$ I-Sar $\left.{ }^{1}-I^{8}\right]$ Ang II binding in the adjacent section. The pattern of the binding $(\mathbf{f})$ and the lacZ (e) completely overlap each other. Masson's trichrome staining $(\mathbf{g}-\mathbf{h})$. (g) Minimum periarterial and interstitial fibrosis in Agtr1 $a^{-/-} \leftrightarrow R O S A$ mice after Ang II infusion. Severe periarterial fibrosis and mild diffuse interstitial fibrosis (h) and moderate interstitial fibrosis (i) in Agtr1 $a^{+/+} \leftrightarrow R O S A$ mice after Ang II infusion. Immunostaining for BrdU (brown color, some are with arrows) counterstained with hematoxylin (purple; a few are with white arrowheads) (j-n). $\mathbf{j}-\mathbf{I}$ and $\mathbf{n}$ are doubly stained for lacZ and BrdU. In Agtr1 $a^{-/-} \leftrightarrow R O S A$ mice after a 2-week Ang II infusion (j), the majority of BrdU-positive nuclei have contact with lacZpositive (blue) cardiomyocytes. In the visual field of j, 36 out of 48 (75\%) BrdU-positive nuclei have contact with ROSA myocytes, although this field contains more Agtr1 $a^{-/-}$myocytes than ROSA myocytes. In contrast, in Agtr1a $a^{++} \leftrightarrow R O S A$ with Ang II infusion (k), BrdU incorporation is unrelated to lacZ staining. In Agtr1 $a^{-1-}$ mice infused with Ang II (m) and in Agtr1 $1 a^{-1-} \leftrightarrow R O S A$ mice without Ang II infusion (I), there is almost no BrdU incorporation. Mild BrdU incorporation in periarterial region of Agtr1 $a^{-/-} \leftrightarrow R O S A$ mice infused with Ang II (n). The distribution of BrdU is unrelated to the lacZ positivity of vascular smooth muscle cells. Scale bars: (a-d, g-n) $0.1 \mathrm{~mm}$; (e and f) $0.5 \mathrm{~mm}$. 
receptors that are visually identifiable by this method reside in cardiomyocytes, with only few in fibroblasts.

Cardiac fibrosis and interstitial cell proliferation in the chimeric beart induced by Ang II infusion. We infused Ang II (1 ng/g body weight $/ \mathrm{min}$ ) in Agtr1 $a^{-/-} \leftrightarrow R O S A$ and $A g t r 1 a^{+/+}$ $\leftrightarrow R O S A$ chimeric mice for 2 weeks using osmotic minipumps. Most chimeric mice developed hypertension. When Agtr $1 a^{+/+} \leftrightarrow R O S A$ and Agtr $1 a^{-/-} \leftrightarrow R O S A$ mouse groups were compared, blood pressure did not differ greatly. Agtr $1 a^{-/-} \leftrightarrow R O S A$ mice with a small contribution of ROSA cells (A1 and A9) showed normal (A9) or slightly elevated (A1) conscious blood pressure (Table 1).

By using Masson's trichrome staining, mild to moderate interstitial fibrosis and perivascular fibrosis were focally observed in all Agtrla $a^{+/+} \leftrightarrow R O S A$ mice (Figure 2, h and i). These fibrotic lesions did not express $\alpha$-smooth muscle actin (data not shown). When the degree of collagen staining was quantified by a point counting method, all Agtrl $a^{+/+} \leftrightarrow R O S A$ mice had total collagen indices $>14.9$ (Table 1). In contrast, only 2 Agtr $1 a^{-/} \leftrightarrow R O S A$ mice (A3, A6) had moderate fibrosis (total collagen index: 26.3 and 27.6), whereas 2 (A2, A5) had very mild fibrosis (total collagen index: 3.8 and 2.4) (Figure 2g), and the other 5 (A1, A4, A7, A8, A9) had almost no fibrosis (total collagen index: $<0.5)$. All Agtr1 $a^{-/-} \leftrightarrow R O S A$ mice, including those without fibrosis, contained ROSA myocytes, interstitial cells, and vascular smooth muscle cells in the adjacent sections. When periarterial fibrosis was selectively evaluated in $A g t r 1 a^{+/+} \leftrightarrow R O S A$ mice, more than half of the arteries had mild (score 1 ) to moderate or severe (score 2 ) periarterial fibrosis. Average periarterial fibrosis indices ranged between 0.43 and 1.19 in $A g t r 1 a^{+/+} \leftrightarrow R O S A$ mice (Table 1). In contrast, 6 Agtrla ${ }^{-/-} \leftrightarrow R O S A$ mice contained no periarterial fibrosis, irrespective of lacZ positivity of vascular smooth muscle cells, fibroblasts, or surrounding myocytes, and only 3 Agtr $1 a^{-1-} \leftrightarrow R O S A$ mice (A4, A5, A6) showed borderline thickening of adventitia in 1 or 2 coronary arteries (Figure $2 \mathrm{~g}$ ). Both in Agtr1 $a^{-/-} \leftrightarrow R O S A$ mice infused with saline alone and in Agtr1 $1 a^{-/}$mice infused with Ang II, there was no fibrosis in the heart (total collagen index: $<0.5$; periarterial fibrosis index: 0 ).

To assess subtle or early changes of cardiac remodeling, we examined cell proliferation using BrdU. BrdU incorporation was observed in the cardiac tissue of all Agtr1 $a^{-/} \leftrightarrow R O S A$ and Agtrl $a^{-/-} \leftrightarrow R O S A$ mice, even in areas without fibrosis. Of note, interstitial cells, but not cardiac myocytes, incorporated BrdU. Morphologically, most BrdU-incorporated cells were nonendothelial cells. There was essentially no BrdU incorporation in the heart of Agtr $1 a^{-/-} \leftrightarrow R O S A$ mice infused with saline alone or in that of Agtr1 $1 a^{-/-}$mice infused with Ang II (Figure 2, 1 and m). We examined the interaction between the proliferation of interstitial cells and Agtrla genotype of the surrounding cardiomyocytes in sections doubly stained for lacZ and BrdU. Interstitial cells adjacent to Agtr1a $a^{+/}$(lacZ-positive) myocytes had more BrdU positivity than those surrounded by Agtr1 $a^{-/-}$(lacZ-negative) myocytes when compared between the areas in close proximity within the same section (Figure $2 \mathrm{j}$ and Table 2). In one Agtr1 $a^{-1-} \leftrightarrow R O S A$ mouse (A9) that had the lowest ROSA cell population, BrdU incorporation was low in both Agtr1 $a^{-/-}$and ROSA cardiomyocyte areas (and there was a tendency that ROSA cardiomyocyte area had more BrdU positivity), but the difference was not significant. When all data obtained from 44 areas of 9 Agtrl $a^{-/-} \leftrightarrow R O S A$ mice were pooled, the ROSA cardiomyocyte area had a 2-fold higher BrdU positivity ratio when compared with the Agtr1 $a^{-/}$cardiomyocyte area (Figure 3). Similar analysis in the Agtr $1 a^{+/+} \leftrightarrow R O S A$ heart found no difference in BrdU positivity between interstitial cells adjacent to ROSA cardiomyocytes compared with wild-type cardiomyocytes (Figure $2 \mathrm{k}$ and Table 2), indicating that the difference in the ROSA2 6 mutation or other genetic background of ROSA and non-ROSA cells had no impact on the fibroblast proliferation.

When periarterial regions were observed in Agtr1 $a^{-/-} \leftrightarrow R O S A$ mice, most arteries in Agtr $1 a^{-/-} \leftrightarrow R O S A$

Table 1

Profiles of the chimeric mice used in Ang II infusion experiment

\begin{tabular}{|c|c|c|c|c|c|c|c|c|}
\hline $\begin{array}{l}\text { Chimera } \\
\text { genotype }\end{array}$ & $\begin{array}{c}\text { Mouse } \\
\text { name }\end{array}$ & $\begin{array}{c}\text { Age } \\
\text { (week) }\end{array}$ & $\begin{array}{l}\text { Weight } \\
(\mathrm{g})\end{array}$ & $\begin{array}{l}\text { External } \\
\text { genitalia }\end{array}$ & $\begin{array}{c}\text { (\%) ROSA } \\
\text { cardiomyocytes }\end{array}$ & $\begin{array}{c}\text { (Systolic/diastolic) } \\
\text { Blood pressure }(\mathrm{mmHg})\end{array}$ & $\begin{array}{l}\text { Total collagen } \\
\text { index }\end{array}$ & $\begin{array}{l}\text { Periarterial fibrosis } \\
\text { index }\end{array}$ \\
\hline \multicolumn{9}{|c|}{ Agtr1 $a^{-/-} \leftrightarrow R O S A$} \\
\hline & $\mathrm{A} 1$ & 8 & 23 & Female & 10 & $134 / 98$ & $<0.5$ & 0.00 \\
\hline & A2 & 8 & 30 & Male & 30 & $149 / 116$ & 3.8 & 0.00 \\
\hline & A3 & 8 & 29 & Male & 40 & $166 / 125$ & 26.3 & 0.00 \\
\hline & A4 & 8 & 29 & Male & 40 & (not measured) & $<0.5$ & 0.20 \\
\hline & A5 & 8 & 30 & Male & 90 & $146 / 105$ & 2.4 & 0.10 \\
\hline & A6 & 14 & 35 & Male & 50 & (not measured) & 27.6 & 0.14 \\
\hline & A7 & 26 & 51 & Male & 40 & $151 / 118$ & $<0.5$ & 0.00 \\
\hline & A8 & 26 & 62 & Male & 40 & $125 / 107$ & $<0.5$ & 0.00 \\
\hline & A9 & 26 & 41 & Male & 5 & $117 / 82$ & $<0.5$ & 0.00 \\
\hline \multicolumn{9}{|c|}{ Agtr $1 a^{+/+} \leftrightarrow R O S A$} \\
\hline & W1 & 7 & 26 & Male & 20 & $154 / 120$ & 15.0 & 1.00 \\
\hline & W2 & 7 & 33 & Male & 20 & $148 / 99$ & 32.4 & 1.31 \\
\hline & W3 & 7 & 31 & Male & 30 & $173 / 143$ & 14.9 & 0.57 \\
\hline & W4 & 14 & 40 & Female & 60 & $149 / 113$ & 74.7 & 1.19 \\
\hline & W5 & 7 & 25 & Male & 10 & (not measured) & 21.1 & 0.92 \\
\hline & W6 & 14 & 26 & Male & 5 & $199 / 147$ & 19.6 & 0.43 \\
\hline
\end{tabular}

Approximate percentage of ROSA cardiomyocyte contribution was determined by lacZ staining in some 10 separate sections. At the end of experiments, conscious blood pressure (systolic/diastolic $\mathrm{mmHg}$ ) was measured directly through a catheter placed in the carotid artery. Total collagen indices and average periarterial fibrosis indices were quantified on Masson's trichrome-stained sections, as described in Methods. 


\section{Figure 3}

BrdU-positivity ratio in Agtr1 $a^{-/-} \leftrightarrow R O S A$ and Agtr $1 a^{+/+} \leftrightarrow R O S A$ hearts. The number of BrdU-positive and -negative interstitial cell nuclei in ROSA and non-ROSA cardiomyocyte areas is counted separately in 5 areas of 9 Agtr $1 a^{-/-} \leftrightarrow R O S A$ mice and 6 Agtr $1 a^{+/+} \leftrightarrow R O S A$ mice. All data obtained from 44 areas for Agtr $1 a^{-/-} \leftrightarrow R O S A$ mice and 29 areas for Agtr $1 a^{+/+} \leftrightarrow R O S A$ mice are pooled, and the values for BrdU-positivity ratio are shown in bars. Data from the posterior wall of the A9 mouse and the anterior wall of W6, which have no ROSA cardiomyocytes, are not included. NS, not significant.

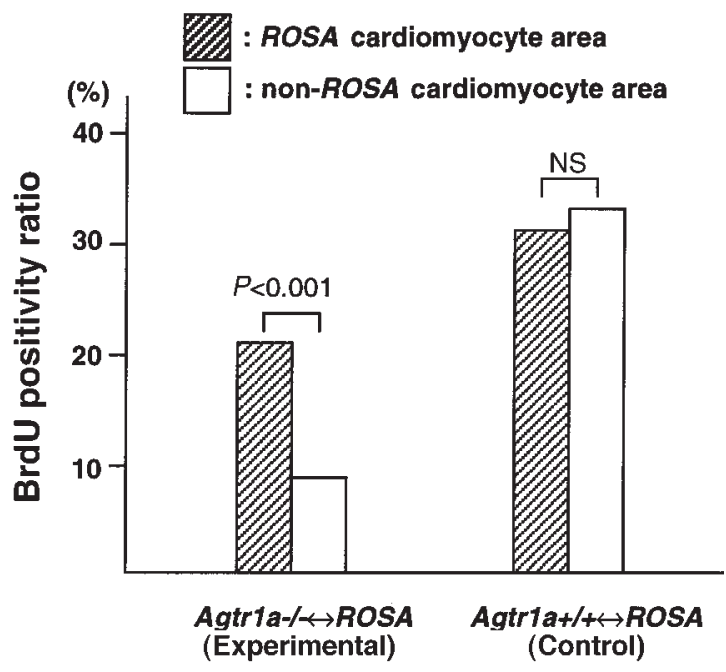

mice had almost no BrdU incorporation, irrespective of lacZ positivity of vascular smooth muscle cells, fibroblasts, and surrounding myocytes. A few arteries in A4, A5, and $\mathrm{A} 6$ showed mild BrdU incorporation in adventitia. In these arteries, no association between BrdU-positive interstitial cells and ROSA vascular smooth muscle cells was observed (Figure 2n).

\section{Discussion}

In the present study, the use of Agtrla $a^{-1-} \leftrightarrow R O S A$ chimeric mice led to several interesting observations that shed new light on cardiac AT1 function, including the cellular expression of AT1 receptor and the Ang II-dependent cardiac fibrosis.

Previous Ang II binding studies $(29,30)$ showed that heart tissues express AT1 receptors. However, because of limited resolution of the method, it was not possible to specify the type of cells (i.e., cardiomyocytes or cardiac fibroblasts) that express AT1 receptor. In vitro studies showed that in cultured neonatal rat cardiomyocytes, specific binding to Ang II is $<10 \%$ of that in fibroblasts (15, 31,32 ). A similar AT1A expression pattern was observed in cultured mouse cardiomyocytes and fibroblasts (our unpublished data). In the present study, the pattern of Ang II binding in Agtr1 $a^{-/-} \leftrightarrow R O S A$ hearts overlaps completely with that of ROSA $\left(\right.$ Agtr1 $\left.a^{+/+}\right)$cardiomyocytes (Figure 2, e and f). By contrast, the pattern of ROSA $\left(\operatorname{Agtr}^{a^{+/+}}\right)$ cardiac fibroblasts did not coincide with the pattern of Ang II binding. Apparently, AT1 receptor expression in cardiac fibroblasts is too low to overcome their small cell size for its detection. Most of the AT1 receptors viewed by this method reside on cardiomyocytes.

Chronic infusion of Ang II in rats induces proliferation of cardiac fibroblasts and synthesis of extracellular matrix proteins in interstitial and perivascular areas (2). Several previous studies suggest that increasing systemic blood pressure may be one mechanism for this Ang II-induced cardiac fibrosis, but other unknown mechanisms also appear to be involved in this process. First, experimental infrarenal aortic banding, which does not induce Ang II, causes blood pressure elevation and cardiomyocyte hypertrophy but not cardiac fibrosis (33).
Second, in animals with experimental renovascular hypertension, the reactive fibrosis is also found in nonhypertrophied right ventricle, where no pressure overload occurs (33). Third, normalization of systemic blood pressure during Ang II infusion by prazosin or hydralazine does not attenuate cardiac fibrosis in rats infused with Ang II $(13,14)$, although the attenuation by hydralazine is not a common finding (13). The prevailing hypothesis for the mechanism underlying Ang II-induced cardiac fibrosis dictates that Ang II directly activates cardiac fibroblasts through its local tissue actions. This is based on several in vitro findings. Thus, cardiac fibroblasts express AT1 receptors $(16,17)$, and Ang II induces mitogenic responses $(18,19)$, and increases protein synthesis (19), production of collagen $(15,17)$, and TGF- $\beta(20-22)$ in cardiac fibroblasts. These studies support the notion that Ang II can directly act on cardiac fibroblasts. In our study, the genotype of each cardiac fibroblast was not clearly defined because of its small cell size and relatively low expression of the lac $Z$ gene. Therefore, our results do not rule out a possible direct effect of Ang II on cardiac fibroblasts. Nevertheless, our results do indicate that AT1 receptors on neighboring cardiomyocytes play an important role in determining the behavior of cardiac fibroblasts in an early phase of cardiac remodeling.

The unique distribution of the cardiac fibroblasts found in the Agtr1 $1 a^{-1-} \leftrightarrow R O S A$ chimeric heart allowed us to document that there is a significant interaction between cardiomyocytes and cardiac fibroblasts; specifically, Agtrla $1 a^{+/}$ cardiomyocytes induce proliferation of neighboring cardiac fibroblasts in response to circulating Ang II. This unique function of Agtr1 $a^{+/+}$cardiomyocytes is attributed to their intact Agtrla gene, not the ROSA26 mutation or other genetic background of the ROSA cells; this is because the proliferative cells were equally observed in ROSA and non-ROSA myocyte areas in Agtr1 $a^{+/+} \leftrightarrow R O S A$ mice, in which non-ROSA cells also carry the intact Agtrla gene.

The observed importance of activated cardiomyocytes in fibrosis is in agreement with a recent transgenic mice study by Molkentin et al. (34). Thus, transgenic mice that overexpress activated forms of calcineurin or NF-AT3 (i.e., calcium-dependent signal-transducing 
molecules) in cardiomyocytes develop cardiac myocyte hypertrophy and cardiac fibrosis. This and our studies indicate that a growth factor(s) is produced by activated cardiomyocytes, which promotes cardiac fibroblasts in a paracrine fashion. One obvious candidate for such a growth factor(s) is TGF- $\beta(14,19,35)$. In the present series of studies, we therefore examined TGF- $\beta 1$ mRNA and protein expression by in situ hybridization and immunostaining methods. No difference in TGF- $\beta 1$ mRNA and protein expression was detected between ROSA cardiomyocyte areas and Agtr1 $a^{-/-}$cardiomyocyte areas (data not shown). However, it is conceivable that the cardiac TGF- $\beta$ activity is regulated not only by alteration in the total amount of TGF- $\beta$ protein but also by the activation rate of the latent form of TGF- $\beta$ (36). Therefore, we cannot presently exclude the possible involvement of TGF- $\beta$ in the paracrine communication between cardiomyocytes and fibroblasts in Ang II-induced cardiac fibrosis.

Previous studies in rats showed that Ang II infusion induces focal necrosis of cardiomyocytes, and fibrosis occurred, replacing these necrotic lesions (2). In Agtr1a $a^{-/} \leftrightarrow R O S A$ mice, $R O S A$ myocytes, which express AT1 receptor, would presumably be more susceptible to Ang II-induced necrosis. In the present study, the areas analyzed for BrdU incorporation did not contain necrotic lesions. It is therefore unlikely that a susceptibility to necrosis is the intermediary mechanism for the observed association between ROSA myocytes and interstitial cell proliferation.

We further examined whether this novel myocyte-fibroblast interaction is observed in the in vitro culture system, in which identification of a specific mediating factor may be possible. Conditioned medium of Agtrla $a^{+/+}$cardiomyocytes with and without stimulation of Ang II was applied to Agtr1a $a^{-/}$cardiac fibroblasts, but no difference was observed in $\left[{ }^{3} \mathrm{H}\right]$ thymidine uptake (data not shown). Also, we cocultured Agtr1a ${ }^{-1-}$ cardiac fibroblasts with Agtr $1 a^{+/+}$cardiomyocytes with or without Ang II stimulation. Again, fibroblasts cocultured with Ang II-stimulated cardiomyocytes did not incorporate a greater amount of $\left[{ }^{3} \mathrm{H}\right]$ thymidine than fibroblasts with nonstimulated cardiomyocytes (data not shown). Therefore, in in vitro systems, cardiac myocytes stimulated by Ang II do not cause appreciable promotion of the growth of cardiac fibroblasts, at least under conditions tested thus far. The discrepancy between the in vivo and in vitro systems may be attributed to changes in cellular characteristics in vitro, which includes downregulation of AT1 receptor. Another possibility is that systemic changes (mechanical or hormonal [ref. 2] stimulation), present in vivo, may be necessary to play a permissive role for cardiomyocyte-mediated fibroblast growth promotion. In fact, when the Agtr1 $a^{-/-} \leftrightarrow R O S A$ and Agtr $1 a^{+/+} \leftrightarrow R O S A$ hearts are compared, the latter have more extensive fibrosis in ROSA cardiomyocyte areas. In addition, the A9 Agtr $1 a^{-1-} \leftrightarrow R O S A$ mouse, which has extremely low contribution of ROSA cells and is not hypertensive, has a very low BrdU incorporation in ROSA cardiomyocyte areas. In this

Table 2

Quantification of interstitial BrdU incorporation in Agtr1 $a^{-/-} \leftrightarrow R O S A(\mathrm{~A} 1-\mathrm{A} 9)$ and Agtr1 $a^{+/+} \leftrightarrow R O S A(\mathrm{~W} 1-\mathrm{W} 6)$ hearts

\begin{tabular}{|c|c|c|c|c|c|c|c|}
\hline \multirow[b]{2}{*}{$\begin{array}{l}\text { Chimera } \\
\text { genotype }\end{array}$} & \multirow[b]{2}{*}{$\begin{array}{c}\text { Mouse } \\
\text { name }\end{array}$} & \multirow[b]{2}{*}{$\begin{array}{c}\text { Adjacent } \\
\text { cardiomyocytes' } \\
\text { type }\end{array}$} & \multicolumn{5}{|c|}{ BrdU positivity ratio in interstitial cells (\%) } \\
\hline & & & $\begin{array}{c}\text { Anterior } \\
\text { wall }\end{array}$ & $\begin{array}{c}\text { Lateral } \\
\text { wall }\end{array}$ & $\begin{array}{c}\text { Posterior } \\
\text { wall }\end{array}$ & Septum & $\begin{array}{c}\text { Right } \\
\text { ventricle }\end{array}$ \\
\hline
\end{tabular}

Agtr1 $1 a^{-/-} \leftrightarrow R O S A$

\begin{tabular}{|c|c|c|c|c|c|c|}
\hline \multirow[t]{2}{*}{$\mathrm{A} 1$} & LacZ+ & $\begin{array}{c}42.6 \\
*\end{array}$ & $\begin{array}{c}18.8 \\
*\end{array}$ & $\begin{array}{c}13.5 \\
*\end{array}$ & $\begin{array}{c}22.1 \\
*\end{array}$ & $\begin{array}{c}21.8 \\
*\end{array}$ \\
\hline & LacZ- & 22.6 & 5.9 & 4.2 & 6.2 & 9.9 \\
\hline \multirow[t]{2}{*}{$\mathrm{A} 2$} & LacZ+ & $\underset{*}{25.1}$ & $\begin{array}{c}30.7 \\
*\end{array}$ & $\begin{array}{c}34.0 \\
*\end{array}$ & $\begin{array}{c}23.5 \\
*\end{array}$ & $\begin{array}{c}36.8 \\
*\end{array}$ \\
\hline & LacZ- & 11.8 & 11.3 & 8.2 & 9.0 & 7.7 \\
\hline \multirow[t]{2}{*}{ A3 } & LacZ+ & $\begin{array}{c}11.0 \\
*\end{array}$ & $\begin{array}{c}23.4 \\
*\end{array}$ & $\begin{array}{c}12.5 \\
*\end{array}$ & $\begin{array}{c}11.8 \\
*\end{array}$ & $\begin{array}{c}9.2 \\
*\end{array}$ \\
\hline & LacZ- & 3.7 & 8.2 & 5.2 & 3.7 & 2.9 \\
\hline \multirow[t]{2}{*}{ A4 } & LacZ+ & $\begin{array}{c}26.6 \\
*\end{array}$ & $\begin{array}{c}45.9 \\
*\end{array}$ & $\begin{array}{c}38.6 \\
*\end{array}$ & $\begin{array}{c}26.9 \\
*\end{array}$ & $\begin{array}{c}16.7 \\
*\end{array}$ \\
\hline & LacZ- & 14.7 & 10.7 & 8.1 & 10.2 & 4.8 \\
\hline \multirow[t]{2}{*}{ A5 } & LacZ+ & $\begin{array}{c}20.2 \\
*\end{array}$ & $\begin{array}{c}27.5 \\
*\end{array}$ & $\begin{array}{c}24.2 \\
*\end{array}$ & $\begin{array}{c}22.1 \\
*\end{array}$ & $\begin{array}{c}23.7 \\
*\end{array}$ \\
\hline & LacZ- & 7.7 & 16.7 & 11.7 & 14.4 & 2.7 \\
\hline \multirow[t]{2}{*}{ A6 } & LacZ+ & $\begin{array}{c}20.6 \\
*\end{array}$ & $\begin{array}{l}7.3 \\
\text { NS }\end{array}$ & $\begin{array}{c}13.2 \\
*\end{array}$ & $\begin{array}{c}16.4 \\
\text { NS }\end{array}$ & $\begin{array}{c}13 \\
*\end{array}$ \\
\hline & LacZ- & 9.6 & 5.1 & 4.9 & 12.3 & 4.8 \\
\hline \multirow[t]{2}{*}{ A7 } & LacZ+ & $\begin{array}{c}17.5 \\
*\end{array}$ & $\begin{array}{c}27.0 \\
*\end{array}$ & $\begin{array}{c}20.9 \\
*\end{array}$ & $\begin{array}{c}29.9 \\
*\end{array}$ & $\begin{array}{c}25.9 \\
*\end{array}$ \\
\hline & LacZ- & 7.1 & 7.0 & 7.0 & 11.9 & 12.5 \\
\hline \multirow[t]{2}{*}{ A8 } & LacZ+ & $\begin{array}{c}17.9 \\
*\end{array}$ & $\begin{array}{c}18.9 \\
*\end{array}$ & $\begin{array}{c}26.8 \\
*\end{array}$ & $\begin{array}{c}17.1 \\
*\end{array}$ & $\begin{array}{c}12.7 \\
*\end{array}$ \\
\hline & LacZ- & 4.7 & 7.8 & 10.7 & 6.2 & 4.1 \\
\hline \multirow[t]{3}{*}{ A9 } & LacZ+ & 8.8 & 13 & 1.1 & 6.1 & 17.3 \\
\hline & & NS & NS & & NS & * \\
\hline & LacZ- & 5.7 & 6.6 & (a) & 6.3 & 2.1 \\
\hline
\end{tabular}

$\operatorname{Agtr} 1 a^{+/+} \leftrightarrow R O S A$

\begin{tabular}{ccccccc} 
W1 & LacZ+ & 41.3 & 30.5 & 47.6 & 19.8 & 22.2 \\
& & $\mathrm{NS}$ & $\mathrm{NS}$ & $\mathrm{NS}$ & $\mathrm{NS}$ & $\mathrm{NS}$ \\
\hline W2 & LacZ- & 37.7 & 30.1 & 38.2 & 16.7 & 18.9 \\
& LacZ+ & 23.4 & 20.6 & 13.1 & 18.5 & 15.3 \\
& & $\mathrm{NS}$ & $\mathrm{NS}$ & $\mathrm{NS}$ & $\mathrm{NS}$ & $\mathrm{NS}$ \\
& LacZ- & 25.2 & 17.4 & 11.3 & 13.0 & 16.7 \\
\hline W3 & LacZ+ & 27.1 & 33.0 & 9.8 & 16.1 & 10.7 \\
& & $\mathrm{NS}$ & $\mathrm{NS}$ & $\mathrm{NS}$ & $\mathrm{NS}$ & $\mathrm{NS}$ \\
& LacZ- & 29.5 & 26.0 & 15.5 & 20.2 & 8.3 \\
\hline W4 & LacZ+ & 70.2 & 34.5 & 20.1 & 48.5 & 8.3 \\
& & $\mathrm{NS}$ & $\mathrm{NS}$ & $\mathrm{NS}$ & $\mathrm{NS}$ & $\mathrm{NS}$ \\
& LacZ- & 68.3 & 32.2 & 18.6 & 52.0 & 7.4 \\
\hline W5 & LacZ+ & 43.0 & 27.8 & 22.8 & 68.9 & 24.7 \\
& & $\mathrm{NS}$ & $\mathrm{NS}$ & $\mathrm{NS}$ & $\mathrm{NS}$ & $\mathrm{NS}$ \\
& $\mathrm{LacZ}-$ & 43.3 & 27.8 & 22.6 & 64.3 & 23.9 \\
\hline W6 & LacZ+ & 69.2 & 60.4 & 71.6 & 36.7 & 21.6 \\
& & $\mathrm{NS}$ & $\mathrm{NS}$ & $\mathrm{NS}$ & $\mathrm{NS}$ & $\mathrm{NS}$ \\
& LacZ- & $(\mathrm{a})$ & 58.7 & 69.6 & 43.7 & 23.8
\end{tabular}

BrdU positivity ratio in interstitial cells that do and do not have contact with lacZ-stained cardiomyocytes was counted separately for each region (anterior, posterior, and lateral walls of left ventricle, septum, wall of right ventricle) in each chimeric heart. $* P<0.01$. (a) No lacZ-positive cardiomyocytes were found in the area. NS, not significant. 
context, the degree of local fibrosis depends also on the total body AT1 receptor number.

Finally, a difference between $A g t r 1 a^{+/+} \leftrightarrow R O S A$ and Agtr $1 a^{-/-} \leftrightarrow R O S A$ was observed in an accentuated manner in periarterial regions. Thus, all $A g t r 1 a^{+/+} \leftrightarrow R O S A$ mice infused with Ang II developed perivascular fibrosis, whereas no (or only subtle) periarterial fibrosis was observed in the Agtr1 $a^{-/-} \leftrightarrow R O S A$ hearts, even in the area surrounded by ROSA cardiomyocytes. There was no association between ROSA vascular smooth muscle cells and BrdU incorporation. Recently, it was shown that pressure overload, produced by constricting abdominal aorta, induced cardiac hypertrophy and cardiac fibrosis in Agtrla $a^{-/-}$mice (37). This and our results suggest that periarterial fibrosis may also be influenced by additional mechanisms, including perfusion pressure.

In conclusion, by using Agtr $1 a^{-/-} \leftrightarrow R O S A$ chimeric mice, we demonstrated that the AT1A receptor resides predominantly in cardiac myocytes and that in response to chronic exposure to Ang II, cardiac fibroblasts proliferate via both systemic and local effects. The latter is mediated by the AT1 receptor function of neighboring cardiomyocytes, indicating that a paracrine communication exists between cardiomyocytes and cardiac fibroblasts.

\section{Acknowledgments}

The authors thank David Threadgill for the gift of ROSA26 transgenic mice and technical advice; Hirotoshi Utsunomiya for technical advice; Edward Price, Jr., Ellen Donnert, and Teresa Bills for technical assistance; Nancy Brown for her helpful comments; and Mary Lee Jones for editorial assistance. This work was supported by National Institutes of Health grants DK44757 and DK-37868. T. Matsusaka is the recipient of a Young Investigator Award from the National Kidney Foundation.

1. Caulfield, J.B., and Borg, T.K. 1979. The collagen network of the heart. Lab. Invest. 40:364-372.

2. Weber, K.T., and Brilla, C.G. 1991. Pathological hypertrophy and cardiac interstitium. Fibrosis and renin-angiotensin-aldosterone system. Circulation. 83:1849-1865.

3. Jalil, J.E., et al. 1989. Fibrillar collagen and myocardial stiffness in the intact hypertrophied rat left ventricle. Circ. Res. 64:1041-1050.

4. Bakth, S., et al. 1986. Arrhythmia susceptibility and myocardial composition in diabetes. Influence of physical conditioning. J. Clin. Invest. 77:382-395.

5. Merx, W., Yoon, M.S., and Han, J. 1977. The role of local disparity in conduction and recovery time on ventricular vulnerability to fibrillation. Am. Heart J. 94:603-610.

6. Michel, J.B., et al. 1988. Hormonal and cardiac effects of converting enzyme inhibition in rat myocardial infarction. Circ. Res. 62:641-650.

7. van Krimpen, C., et al. 1991. DNA synthesis in the non-infarcted cardiac interstitium after left coronary artery ligation in the rat: effects of captopril. J. Mol. Cell. Cardiol. 23:1245-1253.

8. Schieffer, B., et al. 1994. Comparative effects of chronic angiotensinconverting enzyme inhibition and angiotensin II type 1 receptor blockade on cardiac remodeling after myocardial infarction in the rat. Circulation. 89:2273-2282.

9. Jalil, J.E., Janicki, J.S., Pick, R., and Weber, K.T. 1991. Coronary vascular remodeling and myocardial fibrosis in the rat with renovascular hypertension. Response to captopril. Am. J. Hypertens. 4:51-55.

10. Brooks, W.W., et al. 1997. Captopril modifies gene expression in hypertrophied and failing hearts of aged spontaneously hypertensive rats. Hypertension. 30:1362-1368.

11. Pfeffer, J.M., Fischer, T.A., and Pfeffer, M.A. 1995. Angiotensin-converting enzyme inhibition and ventricular remodeling after myocardial infarction. Annu. Rev. Physiol. 57:805-826.

12. Oparil, S. 1994. Cardiovascular health at the crossroads: outlook for the 21st century. Circulation. 91:1304-1310.
13. Crawford, D.C., Chobanian, A.V., and Brecher, P. 1994. Angiotensin II induces fibronectin expression associated with cardiac fibrosis in the rat. Circ. Res. 74:727-739.

14. Kim, S., et al. 1995. Angiotensin II induces cardiac phenotypic modulation and remodeling in vivo in rats. Hypertension. 25:1252-1259.

15. Villarreal, F.J., Kim, N.N., Ungab, G.D., Printz, M.P., and Dillmann, W.H. 1993. Identification of functional angiotensin II receptors on rat cardiac fibroblasts. Circulation. 88:2849-2861.

16. Matsubara, H., et al. 1994. Differential gene expression and regulation of angiotensin II receptor subtypes in rat cardiac fibroblasts and cardiomyocytes in culture. J. Clin. Invest. 93:1592-1601.

17. Crabos, M., Roth, M., Hahn, A.W., and Erne, P. 1994. Characterization of angiotensin II receptors in cultured adult rat cardiac fibroblasts. Coupling to signaling systems and gene expression. J. Clin. Invest. 93:2372-2378.

18. Schorb, W., et al. 1993. Angiotensin II is mitogenic in neonatal rat cardiac fibroblasts. Circ. Res. 72:1245-1254.

19. Sadoshima, J., and Izumo, S. 1993. Molecular characterization of angiotensin II-induced hypertrophy of cardiac myocytes and hyperplasia of cardiac fibroblasts. Critical role of the AT1 receptor subtype. Circ. Res. 73:413-423.

20. Fisher, S.A., and Absher, M. 1995. Norepinephrine and ANG II stimulate secretion of TGF-beta by neonatal rat cardiac fibroblasts in vitro. Am. J. Physiol. 268:910-917.

21. Lee, A.A., Dillmann, W.H., McCulloch, A.D., and Villarreal, F.J. 1995. Angiotensin II stimulates the autocrine production of transforming growth factor-beta 1 in adult rat cardiac fibroblasts. J. Mol. Cell. Cardiol. 27:2347-2357.

22. Sharma, H.S., van Heugten, H.A., Goedbloed, M.A., Verdouw, P.D., and Lamers, J.M. 1994. Angiotensin II induced expression of transcription factors precedes increase in transforming growth factor-beta 1 mRNA in neonatal cardiac fibroblasts. Biochem. Biophys. Res. Commun. 205:105-112.

23. Burson, J.M., Aguilera, G., Gross, K.W., and Sigmund, C.D. 1994. Differential expression of angiotensin receptor $1 \mathrm{~A}$ and $1 \mathrm{~B}$ in mouse. Am.J. Physiol. 267:260-267.

24. Nishimura, H., Matsusaka, T., Fogo, A., Kon, V., and Ichikawa, I. 1997. A novel in vivo mechanism for angiotensin type 1 receptor regulation. Kidney Int. 52:345-355.

25. Matsusaka, T., et al. 1996. Chimeric mice carrying 'regional' targeted deletion of the angiotensin type $1 \mathrm{~A}$ receptor gene. Evidence against the role for local angiotensin in the in vivo feedback regulation of renin synthesis in juxtaglomerular cells. J. Clin. Invest. 98:1867-1877.

26. Friedrich, G., and Soriano, P. 1991. Promoter traps in embryonic stem cells: a genetic screen to identify and mutate developmental genes in mice. Genes Dev. 5:1513-1523.

27. Zambrowicz, B.P., et al. 1997. Disruption of overlapping transcripts in the ROSA beta geo 26 gene trap strain leads to widespread expression of beta-galactosidase in mouse embryos and hematopoietic cells. Proc. Natl. Acad. Sci. USA. 94:3789-3794

28. Hogan, B., Beddington, R., Costantini, F., and Lacy, E. 1994. Manipulating the mouse embryo. A laboratory manual. Cold Spring Harbor Laboratory Press. Cold Spring Harbor, NY. 497 pp.

29. Allen, A.M., Yamada, H., and Mendelsohn, F.A. 1990. In vitro autoradiographic localization of binding to angiotensin receptors in the rat heart. Int. J. Cardiol. 28:25-33.

30. Hunt, R.A., Ciuffo, G.M., Saavedra, J.M., and Tucker, D.C. 1995. Quantification and localisation of angiotensin II receptors and angiotensin converting enzyme in the developing rat heart. Cardiovasc. Res. 29:834-840.

31. Kim, N.N., Villarreal, F.J., Printz, M.P., Lee, A.A., and Dillmann, W.H. 1995. Trophic effects of angiotensin II on neonatal rat cardiac myocytes are mediated by cardiac fibroblasts. Am. J. Physiol. 269:426-437.

32. Harada, M., et al. 1997. Significance of ventricular myocytes and nonmyocytes interaction during cardiocyte hypertrophy: evidence for endothelin-1 as a paracrine hypertrophic factor from cardiac nonmyocytes. Circulation. 96:3737-3744.

33. Brilla, C.G., Pick, R., Tan, L.B., Janicki,J.S., and Weber, K.T. 1990. Remodeling of the rat right and left ventricles in experimental hypertension. Circ. Res. 67:1355-1364.

34. Molkentin, J.D., et al. 1998. A calcineurin-dependent transcriptional pathway for cardiac hypertrophy. Cell. 93:215-228.

35. Roberts, A.B., et al. 1986. Transforming growth factor type beta: rapid induction of fibrosis and angiogenesis in vivo and stimulation of collagen formation in vitro. Proc. Natl. Acad. Sci. USA. 83:4167-4171.

36. Kagami, S., Border, W.A., Miller, D.E., and Noble, N.A. 1994. Angiotensin II stimulates extracellular matrix protein synthesis through induction of transforming growth factor- $\beta$ expression in rat glomerular mesangial cells. J. Clin. Invest. 93:2431-2437.

37. Harada, K., et al. 1998. Pressure overload induces cardiac hypertrophy in angiotensin II type 1A receptor knockout mice. Circulation. 97:1952-1959. 